RU Диагностика остаточных знаний студентов медицинского вуза по естественнонаучным дисциплинам на основе системного подхода

\author{
Чудинский Р. М., Свиридов В. В., Кочукова М. В.
}

\begin{abstract}
Аннотация. Цель исследования состоит в диагностике остаточных знаний по естественнонаучным дисциплинам студентов медицинского вуза посредством применения системного подхода, основанной на определении системных особенностей остаточных знаний при конструировании банка тестовых заданий. В статье приведены опытно-экспериментальные данные исследования динамики удержания объема изученного материала от времени с учетом вида знания. Научная новизна исследования заключается в том, что в нем выявлены особенности диагностики остаточных знаний студентов с применением системного подхода для дисциплин естественнонаучного цикла. В результате проведенного исследования показано отличие контроля текущих знаний от остаточных с учетом психофизиологических параметров сохранности знаний.
\end{abstract}

\title{
EN Monitoring Medical Students' Residual Knowledge in Natural Science Disciplines on the Basis of Systemic Approach
}

\author{
Chudinsky R. M., Sviridov V. V., Kochukova M. V.
}

\begin{abstract}
The research objective includes developing systemic methodology to monitor medical students' residual knowledge in natural science disciplines. The proposed methodology is based on identifying systemic characteristics of residual knowledge that should be taken into account when compiling tests. The article presents results of an experimental study on dynamics of the level of students' residual knowledge on particular disciplines. Scientific originality of the paper lies in the fact that the authors reveal peculiarities of monitoring medical students' residual knowledge in natural science disciplines. The research findings are as follows: the authors identify differences in the methodology of monitoring newly acquired and residual knowledge taking into account psychophysiological characteristics of the knowledge preservation process.
\end{abstract}

\section{Введение}

Актуальность исследования. Обучение естественнонаучным дисциплинам студентов медицинских специальностей составляет фундамент для дальнейшего успешного изучения явлений и процессов, рассматриваемых на клинических дисциплинах и в медицинской практике. Важное значение в прогнозировании дальнейшего эффективного обучения студентов имеет диагностика усвоения материала естественнонаучных дисциплин, поскольку внутрипредметные и межпредметные связи играют интегрирующую роль и обуславливают целостность системы учебного материала разных осваиваемых предметов. Наиболее заметный эффект вклада этих связей из различных областей науки наблюдается при проверке остаточных знаний студентов, то есть 3наний, сохранившихся в памяти студентов спустя некоторое время после изучения дисциплины/темы/раздела.

Изучение научной и методической литературы выявило, что проблема проверки остаточных знаний для естественнонаучных дисциплин разработана недостаточно. Проведенный нами анализ показал, что материал, который используется при тестировании для диагностики знаний, не дифференцируется, несмотря на концептуальные различия текущих и остаточных знаний, а чаще применяется один и тот же банк тестовых заданий. Принимая во внимание, что остаточные знания удерживаются в долговременной памяти, необходимо их включать в систему знания конкретного обучающегося. Следовательно, по своей природе остаточные знания должны быть системными, а значит и задания, применяемые при их проверке, должны конструироваться на основе системного подхода. Учет системных особенностей учебного материала, подлежащего проверке, позволил бы повысить достоверность и объективность результатов тестирования при отсроченном контроле достижений студентов, что соответствует актуальности в условиях реформирования системы образования

Научная статья (original research article) । https://doi.org/10.30853/ped210071

(๔ 2021 Авторы. ООО Издательство «Грамота» (๔ 2021 The Authors. GRAMOTA Publishers). Открытый доступ предоставляется на условиях лицензии СС ВY 4.0 (open access article under the CС BY 4.0 license): https://creativecommons.org/licenses/by/4.0/ 
и внедрения тестирования в качестве наиболее распространенного инструмента оценки качества обучения как на государственном, так и на внутривузовском уровне. Таким образом, актуальность исследования обусловлена недостаточным раскрытием проблемы контроля остаточных знаний студентов для естественнонаучных дисциплин посредством тестирования и определением влияния структуры банка тестовых заданий на результаты тестирования студентов.

Для достижения поставленной цели были поставлены следующие задачи:

- Проанализировать природу, свойства и отличительные признаки остаточных знаний относительно других видов знания.

- Определить теоретико-методологические основы объективного контроля остаточных знаний студентов по дисциплинам естественнонаучного профиля.

- Экспериментально проверить влияние структуры банка тестовых заданий на результаты остаточных знаний студентов по естественнонаучным дисциплинам.

Для решения поставленных задач были использованы следующие методы исследования: изучение и теоретический анализ научной, психолого-педагогической, методической литературы по проблеме исследования (теоретические методы); педагогический эксперимент, тестирование, шкалирование, методы системного анализа, включая использование математической теории графов, психофизиологические методы, математико-статистические методы обработки результатов (эмпирические методы).

Теоретическую базу исследования составили труды в области теоретических и методических подходов к преподаванию естественнонаучных дисциплин: Е. М. Стариковой [18], С. Е. Мансуровой [12], Е. Л. Фейнберга [19], Х. Фрая, С. Кеттериджа, С. Маршалла [23], В. С. Черепанова [20]; исследования, касающиеся применения системного подхода: Ю. М. Плотницкого [16], В. И. Новосельцева [14]; работы о контроле и оценке результатов обучения И. Я. Лернера [11], Ю. Г. Кисляковой [8], Т. В. Лариной [10], Дж. Равена [17]; исследования психофизиологических концепций сохранности знаний: Г. Эббингауза [22], Дж. К. Уайта [25], Р. Вудворста [6], И. М. Гельфанда, В. С. Гурфинкеля, М. Л. Цетлина [7], Д. Нормана [15].

Практическая значимость исследования состоит в том, что полученные результаты могут быть использованы при разработке стратегии повышения достоверности результатов оценки подготовки студентов медицинского вуза при освоении дисциплин естественнонаучного профиля.

\section{Природа, свойства и отличительные признаки остаточных знаний относительно других видов знания}

«Остаточными знаниями» принято считать те знания, которые удерживаются в памяти достаточно длительное время. В психологии роль памяти при этом определяется не только способностью сохранять полученную информацию, но и способностью находить ответы на вопросы, направлять мыслительные процессы, строить умозаключения [4]. Психолог-когнитивист Д. Норман отмечал, что «помнить - это значит успешно справляться с тремя задачами: усвоением, сохранением и повторным извлечением информации. Не помнить - значит не справиться с одной из этих задач» [15, с. 12]. Исследование динамики забывания Г. Эббингаузеном и его последователями выявило, что заученный материал с течением времени забывается независимо от его простоты или сложности, но при этом понимание материала увеличивает время его удержания в памяти человека [22]. Как следствие, в долговременной памяти фиксируются знания, тесно связанные с более ранним опытом, то есть прошедшие процедуру актуализации и структурирования. Физиологи также склонны полагать, что в приобретенной памяти, как и в наследственной, фиксируются лишь «существенные» переменные, «существенные» характеристики [7]. Именно такие знания обуславливают остаточный уровень знаний обучающегося.

Немаловажными характеристиками данного вида знаний являются не только объем, но также структура и качество знаний, удерживаемых в памяти длительное время [8]. Характеристика знания, связанная со структурой изученного, определяющая, что является основным научным понятием, что - основным положением, что - следствием, а что - приложением называется системностью [11], следовательно, знания, сохраняемые в долговременной памяти, обладают также этим свойством. Дж. Равен отмечал, что элементарные знания «не накапливаются и даже при прочном запоминании вряд ли понадобятся когда-нибудь в будущем» [17, с. 54]. Следовательно, материал, применяемый для контроля остаточных знаний, должен отличаться от того, который используется для контроля текущих знаний, и быть направлен в большей степени на проверку системности и взаимосвязанности ключевых компонентов и их логическую структуру.

Таким образом, если целью ставится диагностика остаточных знаний, то будет целесообразно сделать акцент в проверке знаний обучающегося на те, которые составляют систему его знаний.

\section{Теоретико-методологические основы объективного контроля остаточных знаний студентов по дисциплинам естественнонаучного профиля}

Образование в вузе, в отличие от общего образования, в большей степени ориентировано на специфические особенности осваиваемых дисциплин. И даже если получаемое студентом образование имеет гуманитарную направленность в подавляющем большинстве, то успешное освоение естественнонаучных дисциплин связано, в первую очередь, не с природой знаний, а с методикой их освоения. Так, по мнению Е. Л. Фейнберга, 
несмотря на кажущееся «глубокое различие между наукой и искусством, между естественнонаучным и гуманитарным знанием» [19, с. 230], они основываются «на сочетании формально-логического подхода с существенно внелогическими, интуитивными суждениями и решениями. В разных сочетаниях и переплетениях они образуют любой подобный вид деятельности» [Там же, с. 234]. Следовательно, студенту независимо от его специализации для понимания интегральной природы науки необходимо знание периферийных дисциплин. Особо отмечается, что раскрытие прикладной составляющей изучаемых знаний позволяет повысить количество сохраняемых знаний и укрепить их качество за счет установления межпредметных связей [23]. Согласно исследованиям психологов, построение формально-логических схем между фрагментами знаний или представлений об окружающем мире, выбор наиболее значимых связей между предметами и явлениями, выработка алгоритмов действий, дробление информации на блоки наиболее свойственны естественнонаучному мышлению [2; 3; 13]. В этом случае вклад системной составляющей остаточных знаний будет наиболее заметен на материале естественнонаучных дисциплин.

Анализ проблемы оценки качества обучения естественнонаучным дисциплинам показал, что в ряде исследований указывается значимость метапредметных знаний для сохранения принципа фундаментализации образования и преемственности между разными ступенями обучения [1;20;21], но при этом проверка преимущественно направлена на предметные знания и умения [12]. Исследователями указывается и доказывается важность отслеживания остаточных знаний, поскольку они являются узловой точкой перехода к интегральным знаниям от базовых, ускоряют и облегчают этот переход [18], представляют собой «необходимый минимум знаний, достаточный для начала выполнения специалистом своей профессиональной деятельности» [10, с. 10]. Несмотря на признанную важность контроля именно остаточных знаний и их значительный вклад в диагностику качества образования, в исследованиях не до конца раскрыта проблема, посвященная влиянию тестовых заданий, входящих в банк тестовых заданий, на результаты контроля остаточных знаний студентов.

Учесть межпредметные связи, системные компоненты, удерживаемые в памяти студента, при проведении проверочных работ с помощью тестирования возможно посредством использования специально сконструированного на основе системного подхода банка тестовых заданий. На начальном этапе предлагается провести объективную декомпозицию предметной области, построив ее граф на основе методов системного анализа [14; 16] и выделив основополагающие связи и фундаментальные понятия (Рисунок 1) [9]. В вершинах графа располагаются элементарные дидактические единицы (ЭДЕ), ребра графа - это связи между ними, отражающие последовательность, зависимость и т.п.

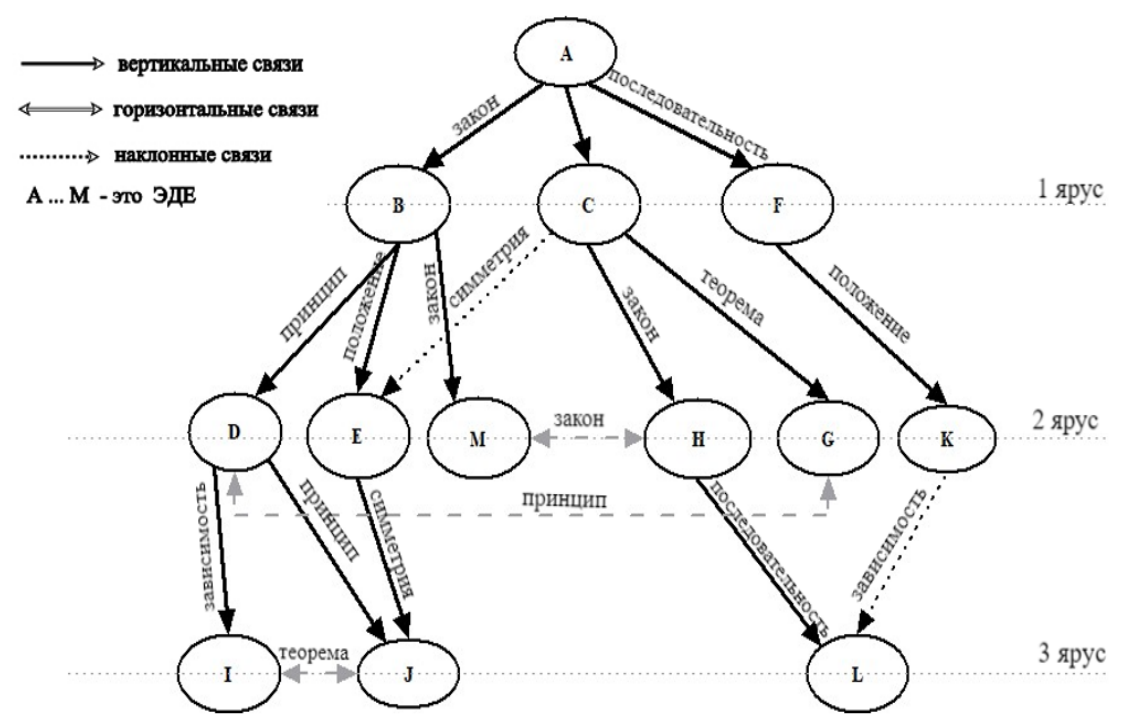

Рисунок 1. Граф декомпозиции предметной области

Наиболее значимые понятия будут расположены на верхних ярусах. Ребра графа также имеют свой вес в зависимости от того, вершины каких ярусов они соединяют. Наиболее значимые понятия расположены на верхних ярусах графа. В зависимости от того, вершины каких ярусов соединяют ребра графа, они имеют свой весовой коэффициент, при этом наибольшим он будет у тех ребер, которые соединяют вершины верхних ярусов.

Структура графа содержит вертикальные связи, характерные для древовидного графа, которые отражают иерархическую зависимость понятий. На эту структуру накладываются горизонтальные связи, позволяющие более полно с содержательной стороны отобразить структуру данной предметной области, и наклонные связи, стабилизирующие в структуре графа положение и иерархию между вершинами.

Для контроля остаточных знаний в банк тестовых заданий рекомендуется включать тестовые задания, проверяющие связи между понятиями, и понятия, расположенные на верхних ярусах графа.

Таким образом, для объективного контроля остаточных знаний студентов по естественнонаучным дисциплинам, чтобы добиться превалирования системности учебного материала над разрозненностью при тестировании, 
следует уже на этапе декомпозиции предметной области, подлежащей проверке, и конструирования банка тестовых заданий применять объективные системные методы. Банк тестовых заданий, состоящий из заданий, связанных факторной структурой знаний, позволяет более достоверно оценить знания, сохраняемые в памяти студентов спустя некоторое время после изучения учебного материала.

\section{Влияние структуры банка тестовых заданий на результаты остаточных знаний студентов по естественнонаучным дисциплинам}

Анализ проблемы влияния структуры банка тестовых заданий на результаты остаточных знаний студентов по естественнонаучным дисциплинам проводился на примере дисциплины «Физика, математика». Студентам в медицинском вузе она преподается на первом курсе. В рамках изучения данной дисциплины обучающиеся не столько познают новое, сколько повторяют ранее изученное и накладывают имеющиеся знания на специализированные сегменты науки. К тому же дисциплина «Физика, математика» связана с другими, поскольку многие понятия, усваиваемые студентами на занятиях, встречаются как на общеобразовательных дисциплинах, например, в физической и коллоидной химии, биохимии, нормальной физиологии, так и на клинических.

Начиная с Г. Эббингауза [22], долговечность сохранения заученного материала исследуется с помощью кривой забывания, которая позволяет проанализировать степень его рассеивания. В зависимости от типа запоминаемого материала кривая может отличаться крутизной ниспадающей части и значением неснижаемого уровня [25]. Процесс рассеивания знаний, как правило, идет по экспоненциальному закону, в котором скорость забывания $(k)$ с течением времени остается постоянной [24]. В нашем исследовании скорость забывания изученного материала $(k)$ выступает показателем эффективности удерживаемых видов знания: системного, основанного на понимании, или элементарного, основанного на репродуктивном заучивании. На каждый из типов знания были созданы банки тестовых заданий. В качестве аппроксиманты мы взяли зависимость:

$$
B(t)=B_{\infty}+\left(B_{0}-B_{\infty}\right) e^{-t k}
$$

где $t$ - время, $B_{\infty}$ - асимптотический уровень доли сохранившихся знаний, $B_{0}=B(t=0), k-$ постоянная скорости забывания.

На констатирующем этапе исследования была выявлена коррелируемость результатов тестирования «остаточных» знаний студентов при использовании банка тестовых заданий с системными тестовыми заданиями (СисТ3), структура которого разработана с основой на предложенный граф (см. Рисунок 1), и банка тестовых заданий с тестовыми заданиями, полученного в результате разбиения учебного материала на элементарные дидактические единицы (ЭДЕ Т3) [5]. На данном этапе было исследовано 178 студентов первого курса Воронежского государственного медицинского университета им. Н. Н. Бурденко по теме «Термодинамика» курса физики. Для сопоставления результатов применялась оценка преподавателя - эксперта, проводившего занятия в течение семестра у студентов.

Проанализированы выборки для «сильных» студентов (тех, у кого баллы от 10 до 8 включительно) - 39 человек и отдельных слабых студентов (тех, у кого баллы от 7 и ниже) - 139 студентов. Результаты представлены на диаграмме (Рисунок 2).

\section{Результаты тестирования по разделу "Термодинамика" курса медицинской физики}

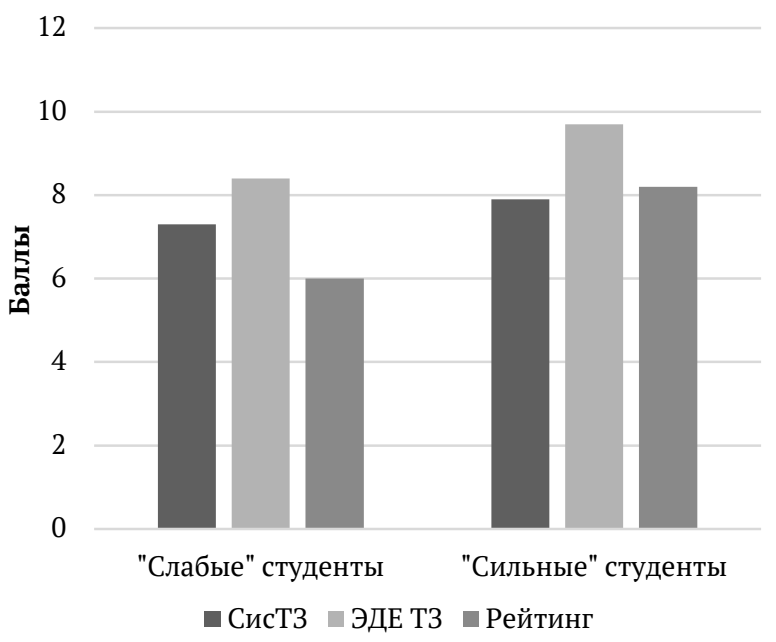

Рисунок 2. Диаграмма диагностики знаний студентов
Коррелируемость

данных эксперимента

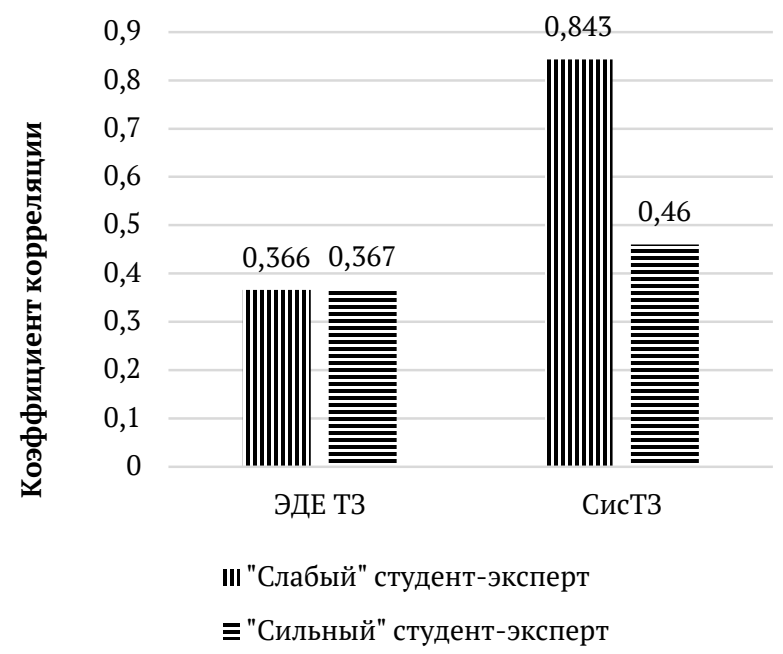

Рисунок 3. Коррелируемость тестовых заданий с оценкой эксперта 
Анализ данных показал, что числовые показатели студентов, полученные за тест, содержащий системные тестовые задания, ближе к оценке преподавателя-эксперта (Рисунок 2). Величина коэффициента корреляции показывает слабую зависимость как для выборки «сильных» студентов независимо от вида тестовых заданий, так и при использовании тестовых заданий на знание ЭДЕ для выборки «слабых» студентов (Рисунок 3). Для системных тестовых заданий на «слабых» студентах коэффициент корреляции указывает на сильную зависимость. Следовательно, банки тестовых заданий, построенные с применением системного подхода, способны уверенно идентифицировать «слабых» студентов. Для «сильных» же студентов менее выраженная ситуация может быть связана либо с малым количеством выборки, либо со слабой дискриминирующей способностью теста в результате превышения уровня подготовленности «сильных» студентов над уровнем трудности большинства заданий, применяемых на констатирующем этапе исследования.

При контроле остаточных знаний, в силу динамики рассеивания с течением времени полученных знаний, уровень знаний большинства студентов будет ближе к уровню текущих знаний «слабых» студентов, что дает основания полагать высокую достоверность полученных данных диагностики знаний при применении системного подхода.

На формирующем этапе эксперимента было проведено тестирование студентов на разных промежутках времени по двум естественнонаучным дисциплинам: физики на массиве 180 студентов и нормальной физиологии на массиве 181 студента. Тест по каждой дисциплине также состоял из двух субтестов в равных пропорциях: один на репродуктивное знание ЭДЕ, другой - на системное знание с учетом связей, понятий и их иерархии, определяемой по предложенному алгоритму декомпозиции предметной области. Первое тестирование проводилось в момент изучения контролируемой темы, остальные спустя некоторые промежутки времени. Согласно работам Г. Эббингауза и его последователей [6;22; 25], уже через месяц после изученного в памяти большую часть составляют остаточные знания.

Оценка эффективности проводилась по значению скорости забывания, поскольку согласно природе знаний системные знания, проверяемые по разработанной технологии, должны демонстрировать меньшую скорость забывания, чем элементарные знания, контролируемые обычными тестовыми заданиями. Расчет коэффициентов уравнения 1 и графическое представление «кривых забывания», отражающих процент удерживаемого в памяти учебного материала от времени (в месяцах) по каждой из дисциплин в зависимости от типа используемых тестовых заданий, приведены на Рисунках 4 и 5.

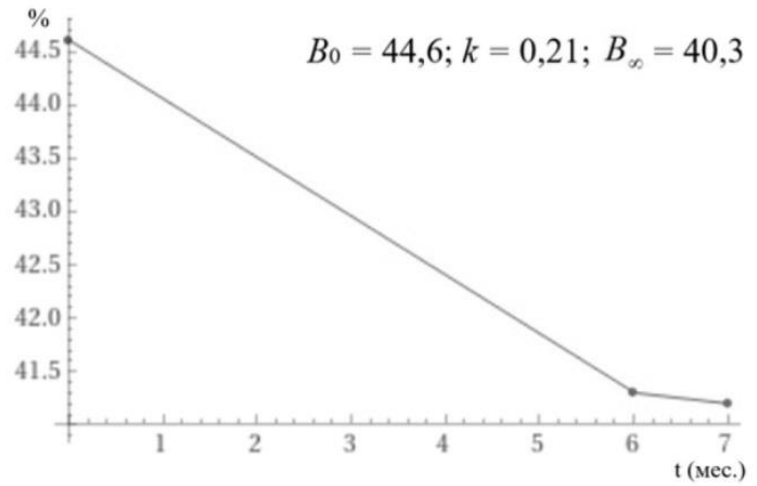

a)

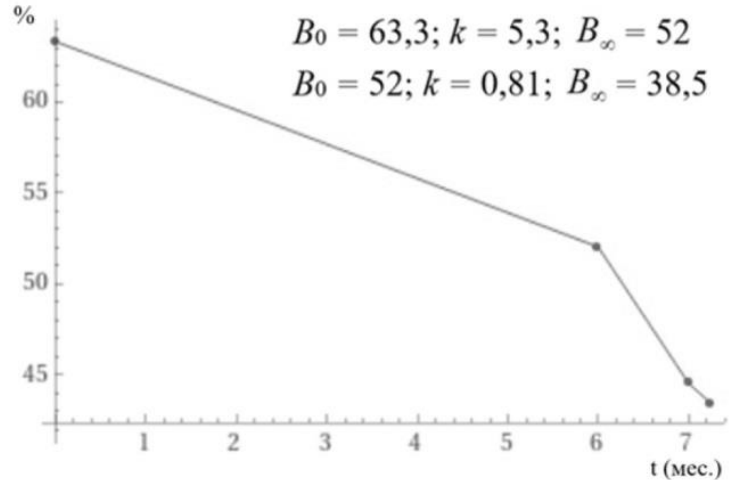

б)

Рисунок 4. «Кривые забывания» знаний по физиологии студентами

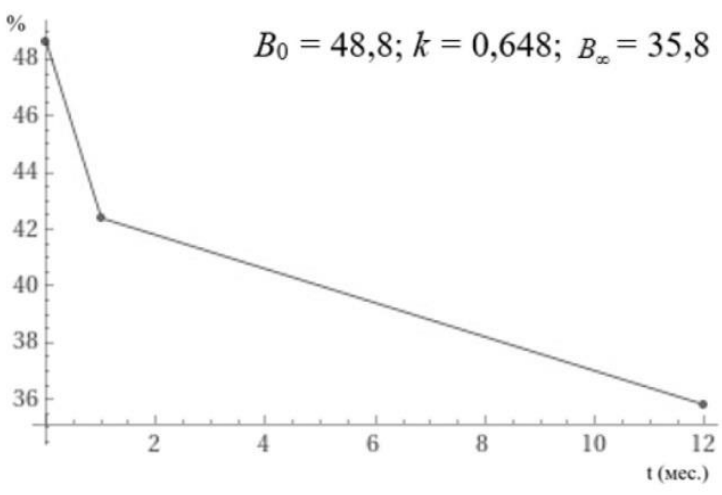

a)

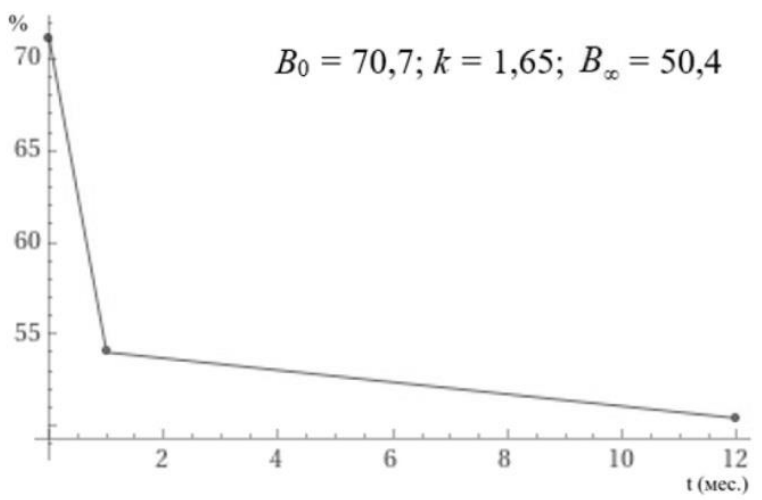

б)

Рисунок 5. «Кривые забывания» знаний по физике студентами 
Изменение уровня знаний студентов, полученное по результатам эксперимента, практически ложится на экспоненциальную кривую. Отступление от графика экспоненты наблюдается для тестовых заданий на знание ЭДЕ по физиологии (Рисунок 4б). На нем кривая делится на два участка: линейной зависимости - до шести месяцев и экспоненциальной - после полугода, для каждого из которых рассчитаны параметры забывания. Учитывая, что больший вклад в остаточные знания вносят знания, удерживаемые в памяти более длительный период времени, целесообразнее учитывать скорость забывания второй части кривой. Также при сравнении полученных «кривых забывания» (Рисунок 4 и 5), видно, что уже через полгода знания студентов становятся «остаточными».

Рассматривая разницу между максимальным и минимальным значениями уровня знаний, наблюдаем близкие значения независимо от вида знаний: для физиологии $\approx 13 \%$, для физики $\approx 27 \%$. Любой материал забывается, независимо от его вида, к тому же в памяти студентов в среднем остается не более $40 \%$ изученного. Существенную разницу в сохранности знаний демонстрирует постоянная скорости забывания $(k)$. Так, константа скорости забывания осмысленных, системных знаний $\left(k_{c u c m}=0,21\right)$ по физиологии (Рисунки 4а и 46$)$

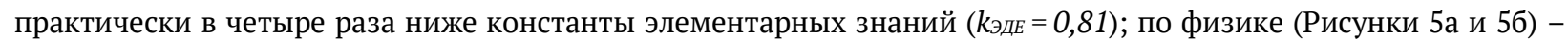

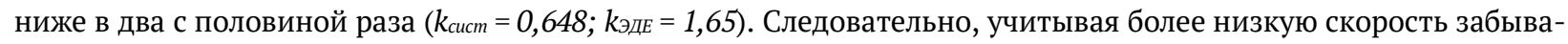
ния системных знаний, для проверки остаточных знаний наиболее оптимальным является применение тестовых заданий, сконструированных по системной технологии.

Таким образом, влияние структуры банка тестовых заданий на результаты остаточных знаний студентов по естественнонаучным дисциплинам вносит существенные изменения в объективность и адекватность числовых результатов студентов. Знания, зафиксированные в памяти посредством только механического запоминания, забываются быстрее и за более короткий промежуток времени, поэтому контроль знаний с помощью обычных тестов, ориентированных на проверку элементарных знаний, даст существенно иные результаты, чем контроль с использованием специально разработанного банка, предназначенного для проверки сохранности системных знаний - остаточных знаний.

\section{Заключение}

Проведенное исследование позволило сделать вывод о том, что контроль остаточных знаний студентов медицинского вуза по естественнонаучным дисциплинам на основе системного подхода отличается от других видов контроля. Остаточные знания системны по своей природе, а их основными отличительными признаками является взаимосвязанность и структурирование.

Сохраненный в долговременной памяти материал входит в систему знаний студента, поэтому в основе объективного контроля остаточных знаний студентов по дисциплинам естественнонаучного профиля должны лежать методы системного подхода, такие как системный анализ, построение графов. Применение системного подхода уже на этапе отбора материала для тестовых заданий позволяет выделить системные компоненты и учесть взаимосвязанность элементарных дидактических единиц. Определенная таким образом структура банка тестовых заданий для контроля остаточных знаний дает возможность получить более объективные и адекватные результаты студентов.

Проведенная экспериментальная проверка влияния структуры банка тестовых заданий на результаты остаточных знаний студентов по естественнонаучным дисциплинам показала, что, учитывая более низкую скорость забывания системных знаний, для проверки остаточных знаний наиболее оптимальным является применение тестовых заданий, сконструированных с применением системного подхода. Следовательно, влияние структуры банка тестовых заданий по естественнонаучным дисциплинам вносит заметные изменения в результаты проверки остаточных знаний обучающихся с увеличением интервала времени, прошедшего после изучения контролируемого учебного материала.

Перспективным направлением исследования представляется применение диагностики остаточных знаний студентов для оценивания компетенций в силу их общей системной природы, а также как составного компонента мониторинга качества образования по естественнонаучным дисциплинам в медицинском вузе.

\section{Источники | References}

1. Анисимова Н. П., Беляева О. А. Метапредметные образовательные результаты школьников как основа формирования универсальных компетенций студентов // Ярославский педагогический вестник. 2018. № 5. С. 57-70.

2. Барсукова Н. И., Лесных Е. А., Обухова Л. Е. Психологические особенности обучения естественно-научным дисциплинам студентов с гуманитарным стилем мышления // Профессиональное образование в современном мире. 2019. Т. 9. № 2. С. 2847-2855.

3. Богомаз С. А. Билатеральная модель структуры психики: дисс. ... д. пед. н. Томск, 1999. 297 с.

4. Бодровская Н. В., Розум С. И. Психология и педагогика: учебник для вузов. СПб.: Питер, 2011. 624 с.

5. Васильев В. И., Киринюк А. А., Тягунова Т. Н. Требования к программно-дидактическим тестовым материалам и технологиям компьютерного тестирования. М.: Московский государственный университет печати, 2005. 29 с.

6. Вудвортс Р. Экспериментальная психология / под ред. Г. К. Гуртового, М. Г. Ярошевского. М.: Изд-во иностранной литературы, 1950. 798 с. 
7. Гельфанд И. М., Гурфинкель В. С., Цетлин М. Л. О тактиках управления сложными системами в связи с физиологией // Биологические аспекты кибернетики: сборник работ / АН СССР; Отд-ние биологич. наук; Науч. совет по комплексной проблеме «Кибернетика»; гл. ред. А. М. Кузин. М.: Изд-во АН СССР, 1962. С. 66-73.

8. Кислякова Ю. Г. Квалиметрическая технология диагностики «остаточных знаний» студентов: дисс. ... к. пед. н. Ижевск, 2002. 158 с.

9. Кочукова М. В., Свиридов В. В. Структурирование предметной области на основе системного подхода // Известия Воронежского государственного педагогического университета. 2017. № 1 (274). С. 92-97.

10. Ларина Т. В. Технология резидуального контроля в образовательном процессе военного вуза (на примере изучения иностранного языка): автореф. дисс. ... к. пед. н. Воронеж, 2006. 26 с.

11. Лернер И. Я. Качества знаний учащихся. Какими они должны быть? М.: Знание, 1978. 48 с.

12. Мансурова С. Е. Проблемы формирования личностных и метапредметных результатов обучения на занятиях по дисциплинам естественнонаучного цикла // Вестник Московского университета. Серия 20. Педагогическое образование. 2017. № 1. С. 36-44.

13. Москвин В. А., Москвина Н. В. Нейропедагогика как прикладное направление педагогики и дифференциальной психологии // Вестник Оренбургского государственного университета. 2001. № 4. С. 34-39.

14. Новосельцев В. И. Системный анализ: современные концепции. Воронеж: Кварта, 2003. 360 с.

15. Норман Д. Память и научение / пер. с англ. Н. Ю. Алексеенко; под ред. П. В. Симонова. М.: Мир, 1985.159 с.

16. Плотницкий Ю. М. Теоретические и эмпирические модели социальных процессов: учеб. пособие для вузов. М.: Логос, 1998. 280 с.

17. Равен Дж. Педагогическое тестирование: проблемы, заблуждения, перспективы / под науч. ред. И. В. Богомолова, Г. В. Бурменской. М.: Когито-Центр, 1999. 144 с.

18. Старикова Е. М. Адаптивная направленность методики обучения основам физики студентов медицинского вуза: автореф. дисс. ... к. пед. н. Челябинск, 2009. 23 с.

19. Фейнберг Е. Л. Две культуры. Интуиция и логика в искусстве и науке. М.: Наука, Главная редакция восточной литературы, 1992. 251 с.

20. Черепанов В. С. О парадоксах наследия и векторах развития образования // Педагогика. 2001. № 2. С. $105-108$.

21. Чупрова О. Ф., Шумовская А. Г. Диагностика метапредметных умений студентов 1 курса: результаты, оценки, выводы // Вестник Иркутского государственного лингвистического университета. 2012. № 4. С. 198-201.

22. Ebbinghaus H. Memory: A contribution to experimental psychology [Электронный ресурс]. URL: http://psychclassics. yorku.ca/Ebbinghaus/ (дата обращения: 19.10.2014).

23. Fry H., Ketteridge S., Marshall S. A Handbook for Teaching and Learning in Higher Education: Enhancing Academic Practice. 3rd ed. N. Y.: Routledge, 2008. 544 p.

24. Rubin D. C., Wenzel A. E. One hundred years of forgetting: A quantitative description of retention // Psychological Review. 1996. Vol. 103. P. 734-760.

25. White G. K. Forgetting functions // Animal Learning and Behavior. 2001. Vol. 29. Iss. 3. P. 193-207.

\section{Информация об авторах | Author information}

RU Чудинский Руслан Михайлович ${ }^{1}$, д. пед. н., доц.

Свиридов Владимир Владимирович ${ }^{2}$, д. физ.-мат. н., проф.

Кочукова Марина Викторовна ${ }^{3}$

1,2 Воронежский государственный педагогический университет

${ }^{3}$ Воронежский государственный медицинский университет им. Н. Н. Бурденко

EN Chudinsky Ruslan Michailovich ${ }^{1}$, Dr

Sviridov Vladimir Vladimirovich ${ }^{2}$, Dr

Kochukova Marina Viktorovna ${ }^{3}$

${ }^{1,2}$ Voronezh State Pedagogical University

${ }^{3}$ Voronezh State Medical University named after N. N. Burdenko

1 chudinsky@mail.ru, ${ }^{2}$ prof.sviridov@mail.ru, ${ }^{3}$ mvk.vsma@gmail.com

\section{Информация о статье | About this article}

Дата поступления рукописи (received): 11.05.2021; опубликовано (published): 30.06.2021.

Ключевые слова (keywords): диагностика; остаточные знания; естественнонаучные дисциплины; системный подход; студенты медицинского вуза; банк тестовых заданий; diagnostics; residual knowledge; natural science disciplines; systemic approach; medical students; test bank. 